\title{
Education for Foreign-Born Students at Japanese Public Schools
}

\author{
Riho Sakurai * \\ Center for the Study of International Cooperation in Education, Hiroshima University, 1-5-1 Higashi Hiroshima \\ City, Hiroshima Prefecture, 739-8529, Japan \\ * E-mail of the corresponding author: riho@hiroshima-u.ac.jp
}

\begin{abstract}
Over the past few decades, the number of foreign-born students registered in Japanese public schools, as well as the number of these students who require Japanese language instruction, have been increasing. However, foreign-born students who need language instruction vary by nationality and live throughout the nation, not necessarily in school zones in which experienced language teachers serve. This makes it difficult to provide extra teachers for only a few students, particularly considering that the Japanese Constitution does not obligate schools to provide basic education for these non-Japanese students. Consequently, an official scheme for Japanese language learning at public schools in Japan was not provided until 2014. The main objective of this study is to explore the dynamics of education for foreign-born students who study at Japanese public schools to examine whether the special language instruction course (tokubetsuno kyoiku katei) given to these students provides a scaffold for cultural diversity and enshrines incisive social development for all children at the school. More concretely, by conducting local teacher interviews at primary and lower secondary public schools, as well as with affiliated language class teachers, and by exploring policies and practices for foreign-born students at Japanese schools, this study delineates the dynamics and challenges of social inclusiveness. The results indicate that Japanese language special instruction classes not only have enabled foreign-born students to become accustomed to the language and the school culture, but the classes have also encouraged mutual personal understanding between Japanese and foreign-born students.
\end{abstract}

Keywords: Foreign-Born Students, Japanese Public Schools, Immigration Policy, Multicultural Understanding DOI: $10.7176 / \mathrm{JEP} / 11-18-22$

Publication date:June 30th 2020

\section{Introduction}

In an attempt to complement the shortfall in the labour force of Japan, which faces the problem of an aging society, the revised immigration control refugee law was established on December $8^{\text {th }} 2018$. The law labels foreign unskilled laborers as either "foreign technical labor category 1," who can live and work in Japan up to 5 years, or as "foreign technical labor category 2," who are permitted to stay in Japan effectively permanently and be accompanied by their families. This technical labor force applies to 14 industries facing labor shortages, including the senior care industry, the cleaning industry, and the food industry, as well as farming, fishing, manufacturing, construction, and ship building (Ministry of Justice, December 8, 2018). With the revised immigration control refugee law having gone into effect on April $1^{\text {st }}$, 2019, Japan has committed to a long-term plan to accept foreign unskilled nationals as foreign workers. This law is a considerable step forward compared to previous immigration laws.

Originally influenced by an amendment to the immigration law in 1990, the "technical intern trainees system" that invites foreign national laborers to Japan as "interns" was introduced in 1993 to "contribute to international cooperation through technical transfer" (Japan International Trainee \& Skilled Worker Cooperation Organization [JITCO], website), yet in reality, foreign laborers have often served as poorly paid interns relegated to unpopular industries and returned to their own countries after a few years, only to re-enter Japan a short time thereafter to engage in the same labor. Over time, though, these egregious working conditions and criminal charges stemming from such dire labor conditions have garnered social concern, as some Japanese industries still continue to face severe shortages in the labor force and thus have to depend on labor from outside the country.

To improve the poor working conditions of foreign technical intern laborers, a law governing the appropriate implementation of technical practice and protection of foreign trainees was enacted on November $1^{\text {st }}$ 2017. With the implementation of this new law, Organization for Technical Intern Training (OTIT) was established to function as a watchdog to ensure that companies hire foreign interns properly. However, this law still maintained that these technical "interns" had to return to their home countries after several years in order to contribute to the development of their own countries through the skills and knowledge that they have obtained through their "intern" work in Japan. The interns' families were also not allowed to accompany them to Japan.

Therefore, the revised immigration control refugee law, which became effective on April $1^{\text {st }}, 2019$ and grants foreign unskilled laborers in the specific industries the chance to officially remain in Japan along with their families (2021 and after) by renewing their visas as many times as necessary, was a major step forward. In other words, this major shift in foreign immigration policy, which only came into effect a little over a year ago as of this writing, stands in stark contrast to previous law and policies on foreign technical, granting unskilled 
manual labor openings in senior care, the food industry, building cleaning, construction, and shipbuilding industry etc. for the foreign workers with the same salary as other Japanese coworkers. While it is expected that a sizable foreign population will be living and working in Japan hereinafter, the revised immigration control refugee law is considered to have a number of pros and cons (c.f. Chugoku Shinbun [Chugoku Area, Japan Newspaper], Nov. 2, 2018), especially as the shift is seen to treat unskilled foreign workers and their families as permanent residents of Japan, which will presumably have a considerable impact on local schools, the local community, the region, and the country at large. The number of foreign-born students registered in Japanese public schools has already exceeded 90,000 as of May 2018 (Figure 1), of whom about 44,000 require Japanese language learning, and well over $90 \%$ of these students are enrolled at primary and lower secondary schools. Therefore, it is critical to examine what is happening on the ground with respect to these foreign children.

While a Japanese language tutoring program was first initiated in 1993, these foreign students of various nationalities who need language instruction are scattered across the nation and do not necessarily reside within school zones with enough experienced language teachers. Due in part to the fact that the Japanese Constitution does not obligate schools to provide public education for foreign national students (Kojima, 2016), it was not until 2014 that the Ministry of Education, Culture, Sports, Science and Technology (MEXT) issued an amendment to the school education law purporting that the special language instruction course (tokubetsuno kyoiku katei) must be included as part of the school curriculum. The amendment ensures that students who require Japanese instruction can be officially pulled out from their regular classes while still receiving credit as part of their formal schoolwork at Japanese public schools. The time allotted to this special Japanese language instruction course has been defined as between 10 to 280 hours per year (MEXT, 2014). However, how does this special Japanese language instruction course function on the ground?

The overall objective of this study is to explore the dynamics of education for foreign-born students in Japanese public schools; more concretely, the study (1) will examine how the special language instruction course given to foreign-born students who require language instruction has been understood on the ground; (2) will explore if the course provides a scaffold for cultural diversity and enshrines inclusion for all children at the school; and (3) will examine how these classes have impacted the rest of the students at the school (c.f. Japanese students). This is a school-based study explored through the perspective of the teachers, and the students included in this study are those receiving the special Japanese language instruction course. In this study, the targeted students are those foreign nationals who fall under one of several categories: those whose mothers and/or fathers are non-Japanese and require Japanese instruction; foreign nationals whose parents are both nonJapanese and who require Japanese instruction; or students who have been granted third country refugee resettlement status. Therefore, this study excludes foreign students who attend international schools or other private schools in Japan, foreign students who attend Japanese public schools but who have already mastered Japanese, or Korean nationals who reside in Japan and who do not need Japanese language instruction.

\section{Previous Studies}

Perspectives about foreign children studying at Japanese public schools are generally negative. Much of the literature holds the view that for these foreign minority students, the majority culture remains unreachable regardless of their language acquisition level or duration of stay or that the goal of any supplementary language classes are to "Japanize foreign students by introducing Japanese culture and norms" (Qi and Zhang, 2008, p.3) and that "the key to educate immigrants is not to try to have better understanding of their cultures, but is to spread understanding of Japanese culture" (ibid, p.9). This could be considered as coercive conformity toward Japanese culture, which is in contradiction to "inherently ethical practice" as described in Liu and Tobin (2018). Tuneyoshi, Okano and Boocock (2011) also denote that ensuring inclusiveness for newly arriving minority foreign students is challenging and is even more so for long-residing Chinese and Korean students as society pushes forward while they remain excluded. Similarly, Nomoto (2009) sheds light on the roles of language instruction class and argues that pulling these students out from the mainstream track does not contribute to mainstreaming these foreign students. He further articulates the essential need of making Japanese language classes provided for foreign nationals more content-based so that students are easily able to merge into the mainstream group. Sugimura (2015) also emphasizes the critical roles of language if the country is trying to promote multiculturalism.

Conversely, Futaba (2016) describes a successful school where inclusiveness has been achieved even in a collective culture like Japan. She argues that a challenging school environment-e.g. with many students with special needs and foreign nationals - can alter school culture through collaboration among parents, teachers, and the community. This change can also come through "adhocracy" or continuous trial and error to ensure rights for all school children. Adding to this, a review of government documents has also revealed that the view towards foreign nationals has generally been passive, viewing them as "weak" or "disadvantaged" (in terms of language) (c.f. MEXT, CLALINET website), yet in 2016, a shift in MEXT could be observed through the perspective of foreign-born students from "passive" to "active," proclaiming that eventually foreign-born students will take a 
leading role in bridging Japan and their native countries, benefiting both societies.

\section{Conceptual Framework}

The theoretical underpinnings for this approach are social network theory and the mere exposure effect (Figure 2). Both frameworks have been applied primarily in social psychology, followed by sociology and anthropology. Social network theory, founded in the 1970s by sociologists (c.f. Bott, 1971; Fischer, 1977, Freeman, 1979, Granovetter, 1973) views social relationships in terms of nodes and ties. Nodes are individual actors in a network, and ties are relationships between the actors in a network. Thus, student relationships can be portrayed under this framework. The "mere exposure effect," originally established by Zajonc (1968), complements this perspective. A large number of papers have applied this theory, and Zebrowitz et al. (2009) argues that people tend to have more familiarity with faces of people from their own race, yet the study revealed that exposure to other races also have increased likeability with respect to "novel faces from that racial category." However, when exposure stimuli were presented in a negative context, the dis-likeability increased and became more negative with increasing exposure; this was particularly true under highly negative conditions (Burgess \& Sales, 1971). Following these frameworks, if Japanese students are exposed to foreign students receiving the special language instruction course under neutral or positive conditions, it shall yield favourable likeability among Japanese and those of foreign students.

\section{Data and Methods}

While there may be a gap between policy and practice on the ground, this paper explores how education or the special language instruction course for foreign-born students has been perceived on the ground. Primary and lower secondary public schools, as well as affiliated language classes in the community in City X (politically designated city) and City $\mathrm{Y}$ in $\mathrm{Z}$ prefecture will be examined. City $\mathrm{X}$ has various interesting aspects in terms of internationalization; for instance, the prefecture holds many descendants of Korean ancestry through "shokuminchika" or by colonialization during the 1910 War, as well as Japanese retirees who served in China during WWII; although the total number of these Korean nationals and Japanese returnees from China has been decreasing. By contrast, the number of Vietnamese and Philippine foreign nationals has drastically increased over the past few years and are similarly increasing in City Y as well. In fact, these two nationals represent almost 50\% of the foreign nationals in City Y, ahead of Korean and Chinese (see Table 1 and Table 2). Further, City $\mathrm{Y}$ stands as the first city in Japan other than the Tokyo-metropolitan area to accept third-country resettlement immigrants ${ }^{1}$ from Central Asian country A. These students of the third country resettlement immigrants were originally from Central Asian country A, immigrated to Southeast Asian country B when they were small, as their parents were persecuted due to religion; therefore, their parents only speak the language of country A at home, even though the children were studying in country B and now in Japan. In a nutshell, old and new foreign nationals reside in prefecture $X$, which makes the prefecture a good case to explore an internationalization policy.

Two schools in City X (one primary school and one junior high school) and one primary school in City Y that have offered the official special language instruction course, as well as schools with large numbers of foreign students who require language instruction, were selected for the study. ${ }^{2}$ The number of foreign students at each school is listed in Table 3. The data collected for the study include dozens of class observations, semistructured interviews with teachers, and archival research. The author visited the schools for observation and conducted hour-long interviews with principals and language teachers. The researcher made 16 school visits and interviewed eight teachers (including principals and assistant teachers involved) for this study.

\section{Results}

Turning to research questions, how has the special language instruction course been conducted on the ground? Results from this study indicate that most classes were designed for teaching Japanese or assisting students in other subjects, as some of the Japanese language embedded in the subject studies are challenging and unfamiliar for foreign students in the special instruction class. Yet the course content does not necessarily impose Japanese culture and or norms to foreign students, but it encourages student exposure to customs of everyday life in Japan, such as the use of a writing board or "shitajiki," for instance. By being exposed to Japanese conventions in this way, foreign students at least become accustomed to Japanese school culture, which was a somewhat different interpretation from Qi and Zhang (2008) described.

\footnotetext{
${ }^{1}$ The Japan has been accepting the third country resettlement immigrant from a Central Asia since 2010. Total number of the third country resettlement immigrants from the inception through the first nine year was 50 families composed of 194 members. Since April 2020 , the number of the resettlement immigrants is defined regularly 60 once a twice per year (Ministry of Foreign Affairs, retrieved from https://www.mofa.go.jp/mofaj/press/release/press4_007824.html and https://www.mofa.go.jp/mofaj/press/release/press4_007888.html ).

${ }^{2}$ There are still few schools which hold a classroom/home for activity for the special language instruction course class. In reality, many licensed language teachers have been dispatched to neighboring schools to deliver the special language instruction course for needed students.
} 
The second research question asks how these language classes have impacted foreign students who are enrolled in the language instruction course. The first answer, unsurprisingly, was that it enabled them to acquire Japanese language skills, but the second answer was that it improved their self-esteem. Students who are disadvantaged often have very low self-esteem, so the language course functions as a facilitator that helps students to maintain their self-assurance, sometimes gaining confidence by being praised. The introduction of these classes has also positively impacted Japanese students as well as other foreign-born students who do not need to take the course.

The third research question asks how these classes have impacted other students at the school. The most important impact was that it encourages internationalization, implicitly raising awareness among Japanese students that there are different cultures. In relation to the impact on Japanese students, one of the principals interviewed for the study concluded that "the class has promoted multicultural understanding and broadened Japanese students' perspectives just as foreign students are facilitating internationalism among Japanese students" (Interview conducted on July $1^{\text {st }}, 2019$ ). The principal further noted that the more time Japanese students spend with foreign students, the more the spirit of collegiality among them is fostered. In other words, the language instruction course has certainly encouraged both Japanese students and the foreign students in the special language instruction course to view each other more as "individuals" and as "friends." Similar views were expressed from principals and language instructors at other schools in both City X and Y. For instance, a teacher in charge of the special language instruction course at B junior high school in City $\mathrm{X}$ relayed the following anecdote.

According to her, when the class went on a school outing the previous year, a foreign-looking student at her school was teased in a discriminatory way by students from another junior high school. In facing this situation, it was a Japanese student at her school who tried to protect her "foreign" student. In an interview, a teacher (K) in charge of the special language instruction course explained the situation to the researcher $(\mathrm{R})$ as follows:

R) Could you share any episodes relating to the students in your special language instruction course?

K) I have a nice story relating to this. We had a school outing last June and we went to the area where almost no foreign students exist.

R) Yes.

K) Then some junior high students were trying to tease with some discriminative words toward this boy, as he looks "very foreign."

K) Then other Japanese students stood up on behalf of him and protected him.

R) Did they fight?

K) No. these students reported to us teachers and we reported to the respective school afterwards. (Emphasis added)

R) I see.

$\mathrm{K})$ But the whole point is that our students were quite upset viewing their foreign classmate teased. I think this illustrates that while foreign students' language proficiency may not be enough, they are already important friends at school.

This episode carries implications in terms of "inclusiveness" and Japanese school culture. Japanese students feel closer to their foreign classmates from the same school than to insular Japanese students from another junior high school. It would be worthwhile to notice that this episode also reveals the hidden Japanese school culture to avoid fighting upfront.

In addition, sometimes the spirit of collegiality has been fostered from the fact that Japanese students understand that foreign students are making efforts to learn Japanese and to understand Japanese culture. The principal continued as follows:

R) Could you share any other stories that touched upon the special language instruction course's influence on those students and on the majority of Japanese students?

K) Sure...let's see...one male student from the Philippines said that he would like to study Japanese as hard as possible so he can communicate with his Japanese father and his Japanese classmates.

R) I see. If I remember correctly, that is the student whose mother remarried three times and each of the three siblings and himself has a different father?

K) Yes, but luckily, his third father was a very nice person. So while this student was living in the Philippines with his grandmother until last year, he could come to Japan to live with his siblings, mother, and this new father. R) He has a complicated family...

K) Yes. But his new father, I mean the youngest sibling's biological father, is really a nice person, playing catch on weekends, reading books before bed, etc., so this student told me that "I would like to study Japanese as hard as I can so that I can communicate with my new father. I also would like to talk more with my Japanese friends. I like Japan."

R) That's a nice story.

$\mathrm{K})$ Yes. And he continues that "if they (Japanese friends) understand that I am making efforts, they are very kind 
and teach me a lot of things. A lot of things."

R) I see. So the majority of students understand that the Filipino student is making efforts let alone progress.

$\mathrm{K})$ Yes, I think that being understood that "making effort" is important, as this makes Japanese students understand that even though these foreign students speak insufficient Japanese, they are making an effort. (The teacher repeated the same thing).

These episodes indicate that attending special Japanese language courses offers not only necessary language skills to the foreign students in the Japanese language class but also gives an opportunity to learn unspoken aspects of Japanese hidden school culture and the long-standing school moral standard that making efforts is beautiful, or doryoku suru koto wa utsukushii in Japanese.

\section{Conclusion}

The special language instruction courses contribute towards an "inclusive environment" for the school, while such language classes, per se, convey manners and norms embedded in Japanese school culture, offering students enrolled in the class opportunities to experience multicultural understanding. As shown in Figure 2, it is through accumulation of daily casual communication and contact between Japanese and non-Japanese students through which many Japanese students have been begun to consider their foreign colleagues as important "friends." However, since the world does not share the same value of regarding "making effort" as a "respectful attitude" at school, it would be worthwhile if these hidden cultural traditions were exhibited to the foreign students in the language course to avoid any misunderstanding. Vice versa, it would further encourage intercultural understanding when different cultural values possessed by foreign students are shown to Japanese students.

This study explored voices of principals, teachers who teach the special language instruction course, and other language teachers who handle foreign-born students requiring language tutelage in two cities in prefecture $\mathrm{Z}$, a local prefecture far from Tokyo. The results indicated quite complicated demographic profiles of foreign students in the language course that would affect not just cognitive learning but all aspects of their lives at school and at home. For instance, interviewed teachers observed that third country resettlement students are often from very solid families yet mostly lack basic learning skills and study customs due to their fragile lifestyle instilled in their original country and further strained by their experience in immigrating to a second country. By contrast, many single-parent students from other Asian countries often lack the strong support of family, including students who can read and write fluently in at least English. Future comprehensive research will convey voices of foreign students, their parent(s), and their siblings so as to understand the challenges encompassing a wider scope of student lives in Japan. In addition to enlarging the scope of the study, it will also be crucial to compare cites nationwide.

While Japan hitherto remains a collective society and an increasingly attractive destination for foreign workers from certain countries, with the revised immigration control refugee law of 2019, soliciting a new channel where mutual collaboration of foreign individuals and Japanese at school and community is imperative in order to lay the foundation of a new diversified society. The special language instruction course clear seems to help bridge the first gap to mitigate prejudice and dilute cultural differences, thereby promoting multicultural understanding among students and beyond.

\section{References}

Bott, E. (1971). Family and Social Network. New York: New York Free Press.

Burgess, T. \& Sales, S. (1971). Attitudinal effects of 'mere exposure' a reevaluation. Journal of Experimental Social Psychology, 7. 461-472.

Chugoku Shinbun (2018). Gaikokujin roudosha to nihon: "Shimin kyoiku" no dounyuga kyumu. [Foreign workers in Japan: Civil education is necessary to open the door to foreign national workers in Japan]. Chugoku Newspaper [Chugoku Regional Newspaper] Nov. $2^{\text {nd }}, 2018$.

E-Stat, Statistics of Japan. Gakko kihon chosa. [school basic survey]. Retrieved from https://www.estat.go.jp/stat-search/files?page $=1 \&$ toukei $=00400001 \&$ tstat $=000001011528 . \quad$ Also, $\quad$ https://www.estat.go.jp/stat-

search/files?page $=1 \&$ query $=\% \mathrm{E} 5 \% \mathrm{~A} 4 \% 96 \% \mathrm{E} 5 \% 9 \mathrm{~B} \% \mathrm{BD} \&$ layout $=$ dataset\&toukei $=00400001 \&$ tstat $=0000$ $01011528 \&$ metadata $=1 \&$ data $=1$.

Fischer, S. (1977). Network and place. -Social relation in the urban setting. New York: The Free Press:

Freeman, L. (1979) Centrality in social networks. Conceptual clarification. Social Network, 1, 215-239.

Futaba, Y. (2016). Inclusive education under collectivistic culture. Journal of Research in Special Educational Needs, 16(1). 649-652.

Granovetter, S. (1973). The strength of weak ties. American Journal of Sociology, 78 (6), 1360-1380.

Gordon J. H., Kariya, T. \& Letendre, G. (Ed.). (2010). Challenges to Japanese education. Economics, Reform, and Human Rights. New York: Teachers College Press. 
Hayashi, A. \& Tobin J. (2015). Teaching embodied. Cultural practice in Japanese preschools. Chicago: The University of Chicago Press.

Kawakami, N. (2015). Mere exposure effect and the unconscious: Where does liking come from? Emotion Studies, 1 (1), 81-86.

Kojima, Y. (2016). Gaikokujin no shugakuto fushuugaku: Shakaide 'Mienai' kodomotachi [Enrollment and Unenrollement of Foreign Students: Invisible Children in the Society]. Osaka: Osaka Daigaku Shuppankai.

Liu, C. \& Tobin, J. (2018). Group exercise in Chinese preschools in an era of child-centered pedagogy." Comparative Education Review, 62, 1, 5-31.

Liu, W., Sidhu, A. \& Beacom, A. (2017). Social network theory. The International Encyclopedia of Media Effects. 1-12.

Japan International Trainees \& Skilled Worker Cooperation (JITCO). Gaikokujin Gino Jishu Seido Toha [What is Foreign Technical Intern Trainee System]. Retrieved from https://www.jitco.or.jp/ja/regulation/.

Matsui, R. (2018). Zainichi Muslim jidono kyoiku shien ni kansuru kenkyu. [A study on Muslim Students at Japanese Public School]. (Unpublished master's thesis). Hiroshima University,

Higashi-Hiroshima, Japan.

Ministry of Education, Culture, Sports, Science and Technology-Japan (MEXT). CLARINET, Children Living Abroad Returnees Internet. Retrieved from https://www.mext.go.jp/a_menu/shotou/clarinet/main7_a2.htm.

Ministry of Education, Culture, Sports, Science and Technology-Japan (MEXT) (2014). Revised School Education Law. Tokyo: Author.

Ministry of Foreign Affairs. Daisankoku Teijunanmin nitaisuru teiju shien program no kaishi [Revision of Facilitating Program for Living in Japan for the Third Country Resettlement Immigrants]. Retrieved from https://www.mofa.go.jp/mofaj/press/release/press4_007888.html.

Ministry of Foreign Affairs. Daisankoku teiju nanmin no teiju saki no kettei [Decisions of Venues of Living for the Third Country Resettlement Immigrants]. Retrieved from https://www.mofa.go.jp/mofaj/press/release/press4_007824.html.

Ministry of Justice (2018). Amended Immigration Refugee Law. Retrieved from http://www.moj.go.jp/nyuukokukanri/kouhou/nyuukokukanri05_00017.html.

Ministry of Education, Education, Culture, Sports, Science and Technology-Japan (MEXT) (2016). Nihongogo shidou ga hitsuyouna jido seito no ukeire jyoukyutou ni kansuru chousa kekka ni tuite [A Survey result on the school registration of primary and junior high school students who need Japanese language instruction]. Author: Tokyo.

Ministry of Education, Education, Culture, Sports, Science and Technology-Japan (MEXT) (2016). Gaikokujin Jidoseiotou ni taisuru kyoiku shienn ni kansuru kiso shiryo [Basic Information on Foreign student's educational support]. Author: Tokyo.

Ministry of Education, Education, Culture, Sports, Science and Technology-Japan (MEXT) (2016). Gakko ni okeru gaikokujin jidoseitotou ni taisuru kyoiku Shien no jyujitsu housaku ni tuite. (Houkoku). [Report on educational support development at school for Foreign Students]. Author: Tokyo.

Ministry of Health, Labour, and Welfare. Ginou jishu hou ni tsuite [Introduction of the appropriate implementation of technical practice and protection of foreign trainees.] https://www.mhlw.go.jp/stf/seisakunitsuite/bunya/koyou_roudou/jinzaikaihatsu/global_cooperation/03.html

Nomoto, H. (2009). Multicultural and multiethnic education in Japan. Educational Studies in Japan: International Yearbook. December, 4, 53-65.

Okubo, Y. (2006). John Ogbu and minority education in Japan. Intercultural Education, 17, 2 May, 147-162.

Qi, J., \& Zhang, S. (2008). The issue of diversity and multiculturalism in Japan. Paper presented at the Annual Meeting of the American Educational Research Association. Orland, Florida. March, 24-29.

Sugimura, M. (2015). Roles of language in multicultural education in the context of internationalization. Educational Studies in Japan: International Yearbook, 9 March, 3-15.

Tsunayoshi, R., Okano, K., and Boocock, S. (2011). Minorities and education in multicultural Japan: An Interactive Perspective. New York: Routledge.

Yokozeki gyosei shoshi jimusho [Yokozeki administrative lawyer office]. Gaikokujin koyouno kyoukasho [Textbook for employing foreign nationals.] Retrieved from https://visa.yokozeki.net/tokutei-ginou/

Zajonc R. (1968). Attitudinal effects of mere exposure. Journal of Personality and Social Psychology Monograph Supplement, 9. (2), Part 2. 1-27.

Zebrowitz, L., White, B., \& Kristin W. (2008). Mere exposure and racial prejudice: Exposure to other-race faces increases liking for strangers of that race. Social Cognition, 26 (3), 259-275.

Riho Sakurai, Ph.D. (M'05-CIES) is an associate professor at the Center for the Study of International Cooperation in Education (CICE) and an affiliated professor with the Hiroshima University Research Center for Diversity and Inclusion. She graduated from the Pennsylvania State University with a dual-title (Ph.D) in 
Education Theory and Policy and Comparative International Education in 2005. Her major field is comparative and international education, and her research interests are inclusive education and education for minority children. Prior to her current position, she served as a full-time teacher at a Japanese school in Aguascalientes, Mexico and was a consultant at the UNESCO Global (Education) Monitoring Report. She was also a postdoctoral researcher at Kyoto University Graduate School of Education.

Figure 1. Foreign students registered at Japanese public schools

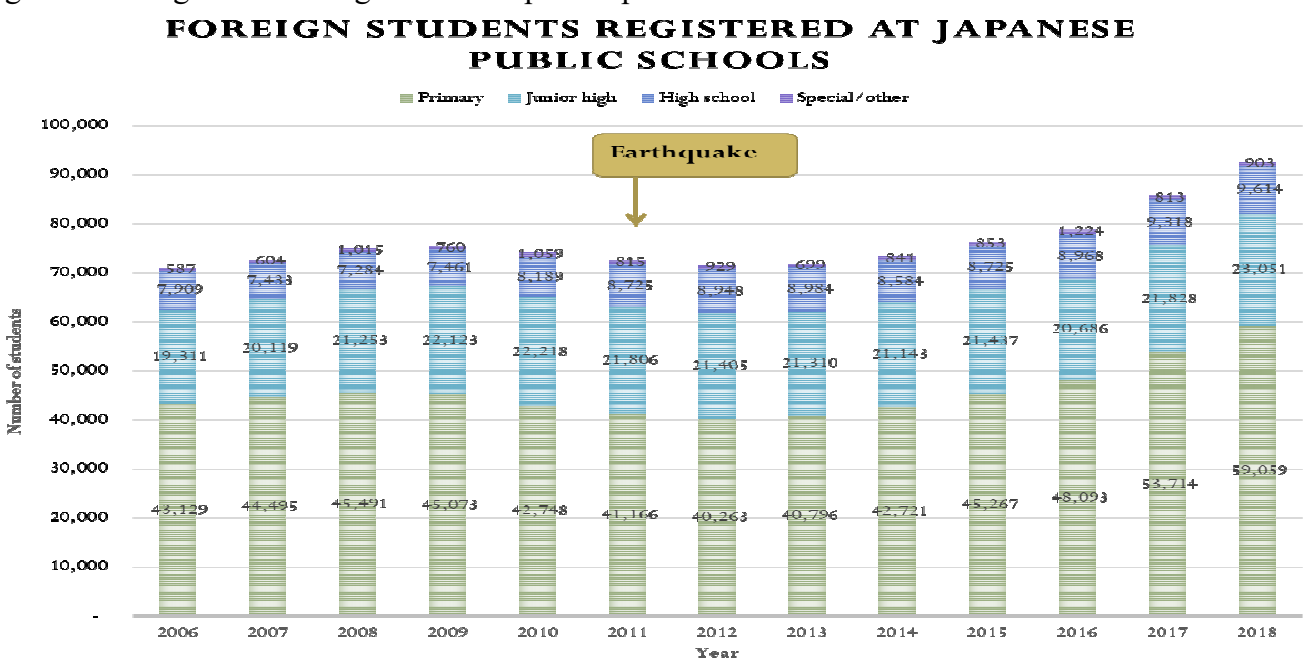

(Source: Author, Assembled from the MEXT Gakko Kihon Chosa, [School Basic Survey] (2019).

Figure 2. Framework of explaining student relationships Relationship

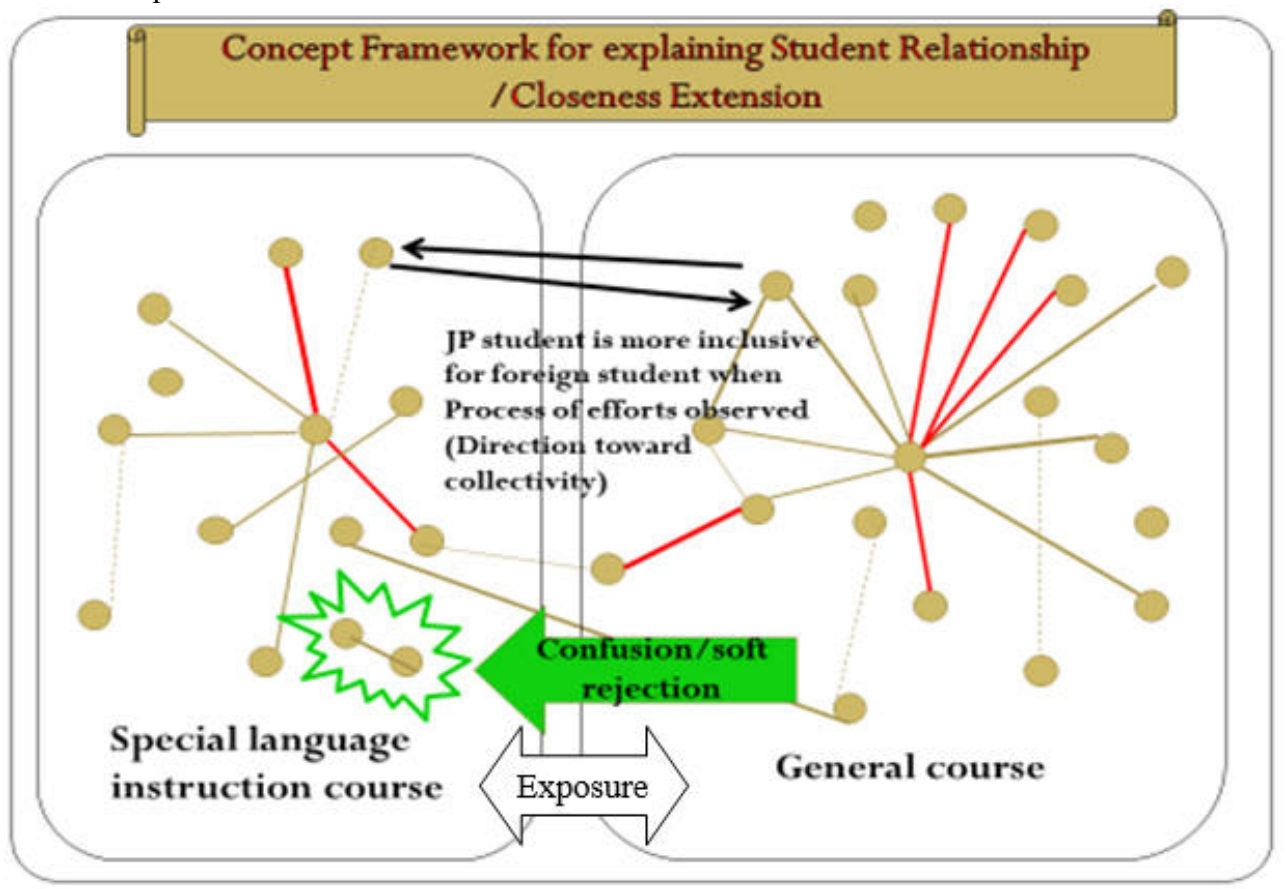

(Source: Author. Referred to Bott, 1971; Fischer, 1977; Freeman, 1979, \& Zajonc, 1968)

Social network theory views social relationships in terms of the following nodes and ties.

Nodes: individual actors in a network; Ties: relationships between the actors within in a network Interdependency: a mutually dependent relationship between nodes 
Table 1. Foreign residents in City X (as of March 2019)

\begin{tabular}{|c|c|c|c|c|}
\hline \multirow{8}{*}{ Foreign Nationals } & Nationality & Total & Rate & Increase/ Decrease \\
\hline & South/North Korea & 5610 & $32.2 \%$ & $\nabla$ \\
\hline & China & 5213 & $29.9 \%$ & $\boldsymbol{\nabla}$ \\
\hline & Vietnam & $\underline{1906}$ & $10.8 \%$ & $\triangle$ \\
\hline & Philippines & 1883 & $10.8 \%$ & $\triangle$ \\
\hline & Brazil & 457 & $2.6 \%$ & - - \\
\hline & USA & 423 & $2.4 \%$ & -— \\
\hline & Other & 1917 & $11 \%$ & \\
\hline
\end{tabular}

(Source: Author, compiled from City X population data)

Table 2. Foreign residents in City Y (as of March 2019)

\begin{tabular}{|l|l|l|l|l|}
\hline \multirow{4}{*}{$\begin{array}{l}\text { Foreign } \\
\text { Nationals }\end{array}$} & Nationality & Total & Rate & Increase/decrease \\
\cline { 2 - 5 } & Philippines & $\underline{\mathbf{8 7 8}}$ & $\underline{\mathbf{2 7 . 3 \%}}$ & $\triangle$ \\
\cline { 2 - 5 } & Vietnam & $\underline{\mathbf{6 8 3}}$ & $\underline{\mathbf{2 1 . 2 \%}}$ & $\triangle$ \\
\cline { 2 - 5 } & China & $\mathbf{5 4 6}$ & $\mathbf{1 7 . 0 \%}$ & $\triangle$ \\
\cline { 2 - 5 } & Brazil & $\mathbf{3 9 6}$ & $\mathbf{1 2 . 3 \%}$ & $\boldsymbol{\nabla}$ \\
\cline { 2 - 5 } & South/North Korea & $\mathbf{3 7 3}$ & $\mathbf{1 1 . 6 \%}$ & $\boldsymbol{V}$ \\
\hline
\end{tabular}

(Source: Author, compiled from City Y population data)

Table 3. Research venues (schools)

\begin{tabular}{|l|l|l|l|}
\hline & $\begin{array}{l}\text { A primary school } \\
\text { (City X) }\end{array}$ & $\begin{array}{l}\text { B junior high school } \\
\text { (City X) }\end{array}$ & $\begin{array}{l}\text { C primary school } \\
\text { (City Y) }\end{array}$ \\
\hline Number of students at the school & 273 & 762 & 647 \\
\hline $\begin{array}{l}\text { Number of foreign students at the } \\
\text { school }\end{array}$ & 50 & 30 & 50 \\
\hline $\begin{array}{l}\text { Number of foreign students who } \\
\text { receives special Japanese lessons }\end{array}$ & 14 & 19 & 8 \\
\hline Countries of origins & $\begin{array}{l}\text { Philippines, Russia, } \\
\text { China, Korea, } \\
\text { Indonesia, Ukraine }\end{array}$ & $\begin{array}{l}\text { China, Philippines, } \\
\text { Nepal, Indonesia }\end{array}$ & $\begin{array}{l}\text { Brazil, Myanmar } \\
\text { Philippines, Indonesia, } \\
\text { Bangladesh }\end{array}$ \\
\hline
\end{tabular}

(Source: Author) 